\title{
Pengelolaan Konten Web Menggunakan Wordpress, Canva dan Photoshop untuk Guru-Guru Wilayah Jakarta
}

\section{Web Content Management Using Wordpress, Canva and Photoshop for Teachers of the Jakarta Region}

\author{
Dian Pratiwi*, Gatot Budi Santoso, Is Mardianto, Agung Sediyono, Abdul Rochman \\ Jurusan Teknik Informatika, Universitas Trisakti, J1. Kyai Tapa, No.1. Jakarta Barat 15000, Indonesia
}

\begin{tabular}{|c|c|}
\hline Info Artikel & ABSTRAK \\
\hline $\begin{array}{l}\text { Diterima 09 Januari } 2020 \\
\text { Ditelaah 13 Mei } 2020 \\
\text { Disetujui } 28 \text { Juni } 2020 \\
\text { Tersedia daring } 30 \text { Juni } 2020 \\
\text { *Penulis untuk korespondensi } \\
\text { dian.pratiwi@trisakti.ac.id } \\
\end{array}$ & $\begin{array}{l}\text { Web merupakan sarana yang telah banyak digunakan untuk berbagi informasi oleh } \\
\text { masyarakat. Namun, dalam pengelolaan kontennya, tidak sedikit pihak yang belum } \\
\text { mengetahui caranya dengan baik, termasuk guru sekolah menengah umum dan dan } \\
\text { kejuruan. Oleh sebab itu, pelatihan pengelolaan konten web berbasis wordpress } \\
\text { diterapkan kepada pihak guru guna membantu mereka dalam menjalankan dan } \\
\text { mengelola web. Pelatihan ini diawali dengan pemberian materi mengenai perancangan } \\
\text { logo dan banner dengan menggunakan Photoshop dan Canva. Kemudian, kegiatan } \\
\text { dilanjutkan dengan praktik cara registrasi domain dan pelatihan membuat e-commerce } \\
\text { dengan content management system Wordpress. Dari hasil kuisioner evaluasi pelatihan } \\
\text { ini, sebanyak 69\% peserta merasa puas dalam penyampaian materi dan 100\% } \\
\text { menyatakan bahwa pelatihan pengelolaan web sangat diperlukan untuk dipelajari dan } \\
\text { diterapkan di sekolah. }\end{array}$ \\
\hline & ABSTRACT \\
\hline $\begin{array}{l}\text { Keywords: } \\
\text { Canva, } \\
\text { CMS, } \\
\text { Photoshop, } \\
\text { Wordpress }\end{array}$ & $\begin{array}{l}\text { The web is a tool that has been widely used to share information with the public. } \\
\text { However, in managing the content, not a few parties who do not know how to do it well, } \\
\text { including high school and vocational school teachers. Therefore, WordPress-based web } \\
\text { content management training is applied to the teachers to assist them in running and } \\
\text { managing the web. The training began with the provision of material on designing logos } \\
\text { and banners using Photoshop and Canva, then practice how to register domains and } \\
\text { training in making e-commerce with WordPress Content Management System. From the } \\
\text { results of the training evaluation questionnaire, as many as } 69 \% \text { of participants were } \\
\text { satisfied in delivering the material and } 100 \% \text { stated that web management training was } \\
\text { needed to be learned and applied in schools. }\end{array}$ \\
\hline
\end{tabular}

ISSN 2685-0354 (Media Online). Diterbitkan oleh Universitas Prof. Dr. Hazairin, SH. Ini merupakan jurnal bebas akses di bawah lisensi Creative Commons Atribution 4.0 International (https://creativecommons.org/licenses/by/4.0

\section{PENDAHULUAN}

Pengelola konten merupakan bidang pekerjaan yang saat ini mulai banyak diperhatikan mengingat perannya untuk selalu menyajikan informasi terbaru yang dimiliki perusahaan atau organisasi untuk segera diketahui masyarakat luas. Keberadaan pengelola konten sangat diperlukan dalam organisasi termasuk di bidang pendidikan. Kini, baik sekolah maupun universitas telah banyak didukung dengan perangkat komputer dan jaringan internet guna mempermudah sumber daya manusia yang ada di dalamnya untuk mencari informasi, menambah ilmu pengetahuan, dan mempercepat penyelesaian pekerjaan.

Pengetahuan tentang Content Management System (CMS) WordPress untuk mengelola website masih sangat rendah bagi pihak sekolah (terutama para guru). Bahkan dalam observasi yang telah dilakukan di beberapa sekolah 
menengah atas (SMA) dan kejuruan (SMK) di Jakarta, umumnya para guru, baik guru pengajar ilmu pengetahuan alam maupun ilmu pengetahuan social, hanya mengetahui cara mengisi atau menulis blog seputar mata pelajaran. Para guru belum mengetahui pengelolaan website berbasis CMS lebih jauh. Untuk itu, pelatihan ini dilaksanakan guna membekali kemampuan guru dalam mengolah isi website menjadi lebih baik.

Keilmuan dan keahlian bidang pengelolaan konten berkembang seiring dengan kemajuan teknologi informasi. Terdapat dua jenis perangkat lunak dalam teknologi informasi yaitu perangkat lunak yang ber-lisensi dan yang bersifat open sources. Model pengembangan perangkat lunak berbasis open source dilakukan dengan cara memberikan kebebasan bagi semua orang untuk melihat dan mengetahui serta mengubah kode perangkat lunak tersebut. Seseorang yang memiliki kemampuan pemrograman memadai dapat melakukan perbaikan agar bugs dan kelemahan-kelemahan yang ada dapat dihilangkan. Dengan adanya bantuan-bantuan pihak luar untuk memperbaiki bugs dan kelemahankelemahan dalam suatu perangkat lunak maka pengembangan metode ini diharapkan dapat meningkatkan perfoma perangkat lunak yang dikaji.

Lisensi dalam pengertian umum dapat diartikan sebagai izin. Pemberian lisensi dapat dilakukan jika ada pihak yang memberi lisensi dan pihak yang menerima lisensi. Hal ini termasuk dalam sebuah perjanjian. Pada umumnya, perangkat lunak yang berlisensi tersebut harus dibayar untuk mendapatkannya. Berbeda dengan aplikasi CMS yang pada umumnya bersifat open source seperti WordPress dan Blogger. CMS Wordpress inilah yang diterapkan dalam kegiatan pengabdian kepada masyarakat ini.

WordPress merupakan sebuah sistem atau perangkat lunak pengelolaan konten web open source yang sangat mudah digunakan dan diintegrasi, serta mempunyai kebebasan pola desain Model View Controller atau MVC (Williams, Damstra, \& Stern, 2015). Bentuk dari sistem Wordpress ini sendiri ada bermacam, diantaranya adalah berbasis web, desktop serta mobile. Selain itu, perangkat lunak ini memiliki banyak kelebihan seperti memiliki komunitas pengguna yang besar dan dinamis, jumlah blog wordpress yang telah banyak tersebar, isu keamanan yang tinggi, memiliki kemudahan dalam perubahan desain, mudah digunakan/dipelihara (Terada, 2017), dan dikembangkan (Prelovac, 2009). Plugin-plugin, baik yang gratis maupun berbayar, membuat WordPress menjadi salah satu aplikasi open source yang paling banyak dipakai untuk mengelola konten.

WordPress memiliki 2 versi, yaitu WordPress.com dan WordPress.org. Keduanya memiliki banyak fungsi yang sama. Namun, perberbedaannya adalah pada WordPress.com, fitur kontrol cascading style sheet berbayar, akses templat dan kode utama yang tersedia, serta tidak memiliki kemampuan instalasi plugin (Sabin-Wilson, 2017). Beberapa keunggulan yang dimiliki oleh WordPress menjadikan CMS tersebut lebih berkembang dan banyak dipakai oleh pengelola konten web.

Hal ini menjadi dasar pelatihan ini yaitu guna memberikan pengetahuan lebih lengkap tentang cara mengelola konten web melalui WordPress kepada guru-guru seluruh mata pelajaran agar dapat dimanfaatkan sebagai sarana pemberi informasi, baik informasi pelajaran maupun konten ujian online. Selain WordPress, peserta juga dibekali kemampuan dalam mendesain dengan menggunakan aplikasi online Canva dan Photoshop. Aplikasi tersebut dipilih berdasarkan hasil wawancara ke tiap peserta sebelum pelaksanaan kegiatan. Canva dan Photoshop merupakan aplikasi yang masih belum dikenal oleh para peserta, terutama Canva.

\section{METODE}

Persiapan dilakukan selama satu bulan (awal bulan Agustus 2019) sebelum pelaksanaan. Persiapan dimulai dari survai dan observasi ke beberapa sekolah di Jakarta untuk mengetahui permasalahan seputar penyampaian materi pelajaran dan kemampuan para guru dalam bidang teknologi, penyiapan materi dalam bentuk modul tercetak dan digital (power point dan video), kesiapan sarana berupa perangkat komputer dan jaringan internet yang memadai, instalasi perangkat lunak Photoshop di setiap komputer, dan pengujian hosting. Pelatihan dilaksanakan dalam beberapa sesi tutorial dengan paparan di depan kelas dan petunjuk teknis yang terdapat dalam video pelatihan, pada hari Sabtu, tanggal 14 September 2019 dengan topik

1. Pemanfaatan Photoshop untuk desain banner dan logo.

2. Perancangan banner dan logo web secara online melalui Canva oleh tim dari mahasiswa (Gambar 1).

3. Cara membuat hosting dan domain.

4. Pembuatan aplikasi e-commerce dengan CMS WordPress

Sebanyak delapan belas belas orang guru yang hadir dalam pelatihan dari 35 orang yang mendaftar (Gambar 2). Para peserta disediakan komputer dan akses internet. Evaluasi dilakukan sebelum dan sesudah pelatihan untuk mengetahui dampak kegiatan terhada kemampuan peserta sesuai dengan tujuan kegiatan. 


\section{HASIL DAN PEMBAHASAN}

Kegiatan pengabdian kepada masyarakat (PKM) ini merupakan rangkaian kegiatan yang sudah dilakukan oleh Jurusan Teknik Informatika, Universitas Trisakti. Kegiatan melibatkan guru-guru di tingkat SMA/SMK. Dari beberapa kegiatan PKM sebelumnya dan kegiatan saat ini disimpulkan bahwa kebutuhan program pelatihan yang lebih berkesinambungan dan rutin diperlukan oleh semua guru mengingat manfaat yang dapat diberikan terhadap pihak sekolah dan telah meluasnya pengetahuan di bidang teknologi indormasi saat ini terutama tentang pengembangan dan pengelolaan website.

Pada saat pelatihan berlangsung pada sesi pembuatan desain banner dengan menggunakan Photoshop dan Canva, hampir setiap guru dapat menyelesaikannya dengan baik. Para peserta mengikuti tahapan yang diberikan oleh pemateri. Banner tersebut kemudian akan dipasang di dalam website yang akan mereka buat melalui CMS WordPress. Dari hasil pengisian kuisioner seluruh peserta yang hadir, 100\% peserta belum pernah menggunakan tools online Canva. Sedangkan untuk Photoshop, 2 orang dari peserta sudah pernah menggunakannya. Begitu pula dengan WordPress, yang sudah ada 3 guru yang telah mempunyai blog pribadi menggunakan WordPress,

Photoshop yang memiliki kemudahan dalam mengubah dan mengkreasikan suatu desain, merupakan perangkat lunak yang bersifat berbayar. Dalam pelatihan ini, Photoshop yang digunakan berversi Photoshop CS, dimana fungsifungsi yang digunakan disesuaikan untuk laman web, seperti eyedropper, browser preview, dan lain-lain (Obermeier \& Padova, 2015).

Canva merupakan perangkat lunak online yang secara gratis disediakan melalui url: https://www.canva.com/. Perangkat lunak ini dikembangkan oleh Melanie Perkins dan diperkenalkan pertama kali di Australia pada tanggal 1 Januari 2012, dimana dalam tahun pertama peluncurannya telah mencapai 750.000 pengguna (Donchev, 2017).

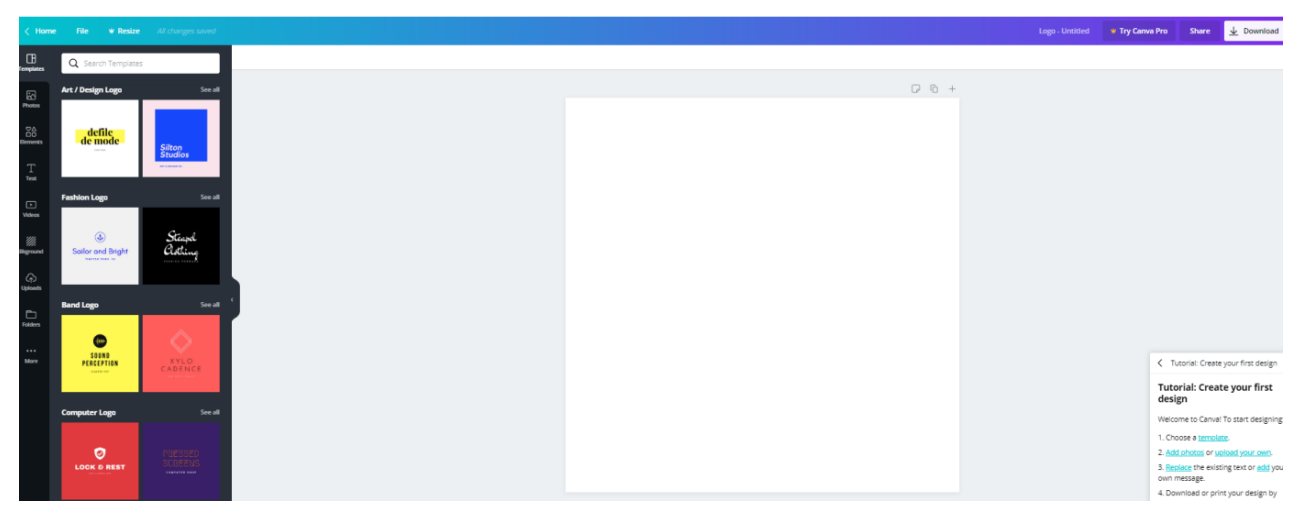

Gambar 1 Lembar Kerja Canva

Domain merupakan nama website yang akan diluncurkan di dalam browser dan harus bersifat unik. Menurut (Pollock, 2013), nama domain sebaiknya dipilih sependek mungkin untuk mengurangi kesalahan pencarian ataupun pengejaan (spelling error). Sedangkan untuk hosting, menurut (Tauhid, 2013) web hosting yang memiliki proses pembayaran serta registrasi yang mudah adalah Web Hosting Server Indonesia dengan menggunakan URL https://www.hostinger.co.id/web-hosting.

Sepanjang kegiatan, beberapa peserta mengusulkan beberapa ide kegiatan yang mungkin dapat dilakukan di masa mendatang. Hasil evaluasi terhadap jalannya pelatihan dan penilaian terhadap kemampuan pembicara dalam menyampaikan materi pelatihan menunjukkan pelatihan berjalan dengan baik dan peserta mampu mengikuti (cukup mampu dan sangat mampu) acara dengan baik (Gambar 5). dalam kaitannya dengan manfaat penggunaan internet dan website bagi keberhasilan mengerjakan pekerjaan para guru di sekolah.

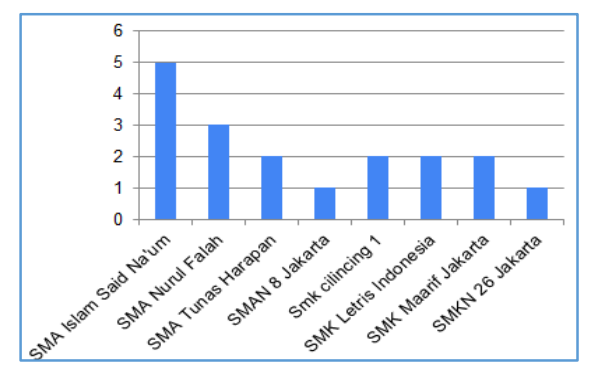

Gambar 2 Grafik Asal Sekolah Peserta 


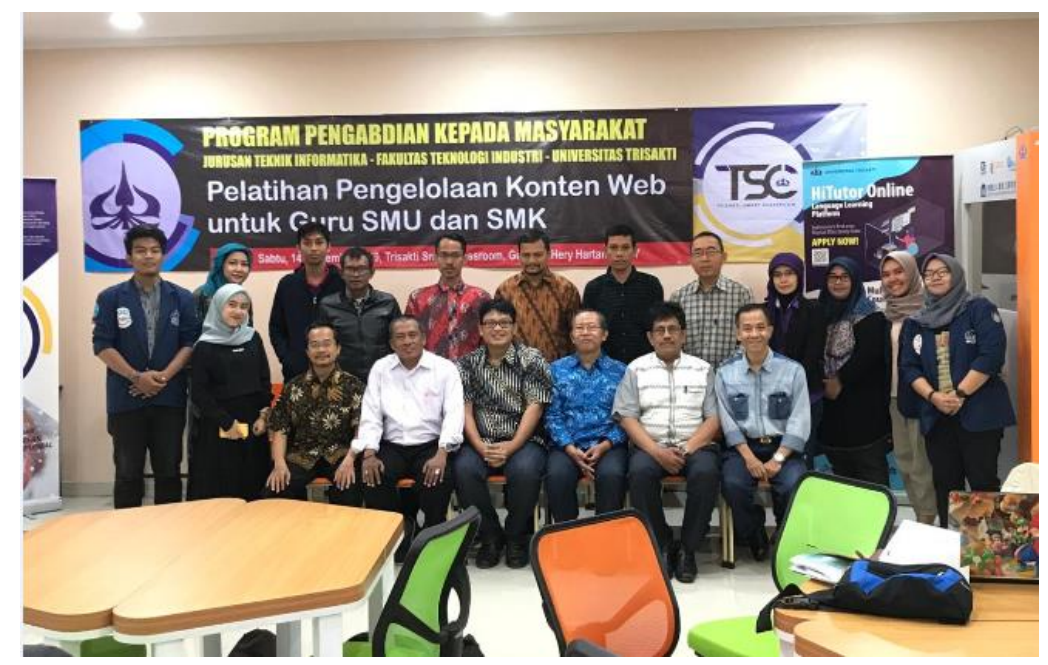

Gambar 3. Panitia dan Peserta Pelatihan

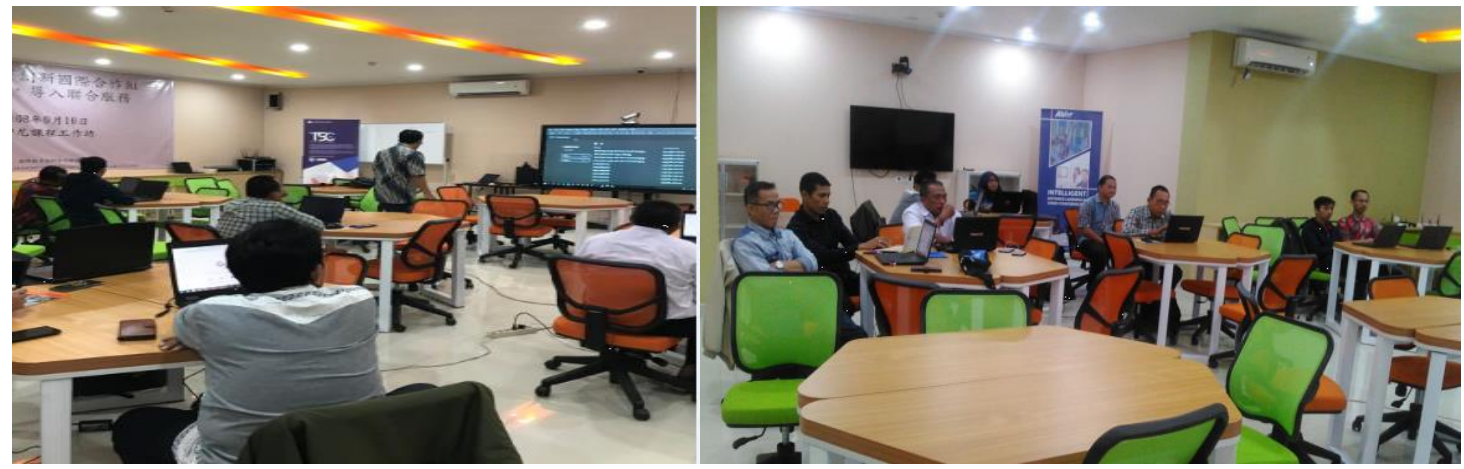

Gambar 4. Suasana Pelatihan

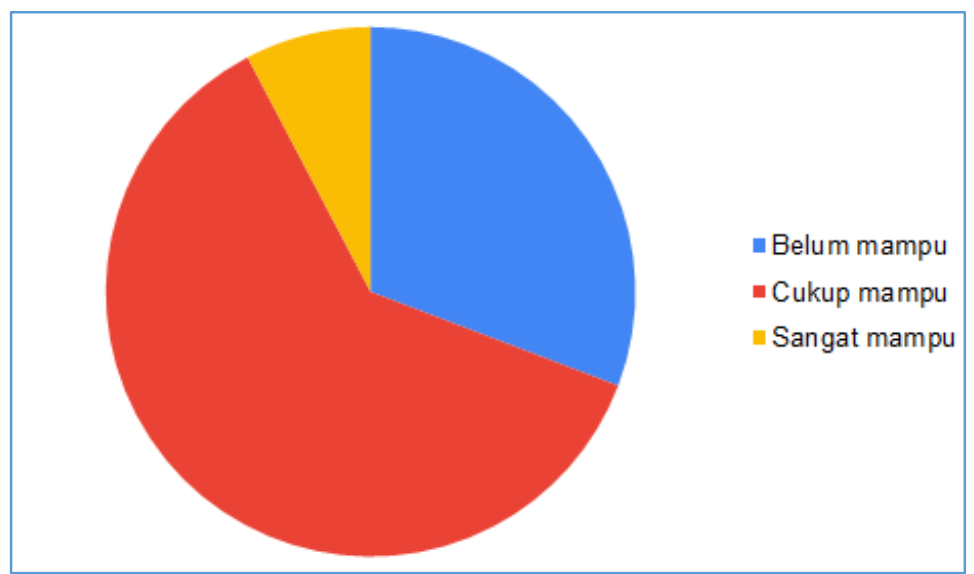

Gambar 5 Pernyataan kemampuan penguasaan materi pelatihan oleh peserta

Setelah dianalisis, peserta PKM yang mengikuti pelatihan ini sebanyak 51\% dengan mayoritas laki-laki yaitu 18 orang dari 35 guru yang mendaftar dengan rincian sebanyak 5 guru dari SMA Said Naum, 3 guru dari Nurul Falah, 2 guru Tunas Harapan 2, 2 guru SMK Cilincing I, 2 guru SMK Letris Indonesia, 2 guru SMK Maarif, 1 guru SMA 8 Jakarta, dan 1 guru dari SMKN 26 (Gambar 2, Gambar 3, Gamba 4). Dari segi kemampuan mengikuti jalannya pelatihan, peserta menyatakan cukup mampu. Hal tersebut terlihat hasil kuisioner (Gambar 5), dan pada hasil konten website yang mereka kelola serta banner yang telah peserta buat cukup bagus. Dengan demikian, pelatihan pengelolaan konten web dapat dikatakan cukup bermanfaat diterapkan kepada para guru dan layak untuk dapat dilanjutkan ke materi pengelolaan konten web yang lebih kompleks pada pelatihan berikutnya. 


\section{KESIMPULAN}

Dari sisi materi tema pelatihan, peserta menilai materi Pengelolaan web dengan sangat diperlukan untuk bisa dipelajari dan diterapkan di sekolah, dan $100 \%$ peserta yang hadir belum pernah menggunakan perangkat lunak online Canva untuk mendesain banner website. Dari sisi penyampaian materi, walaupun 69\% peserta merasa puas tetapi masih ada yang belum peserta yang belum terpuaskan, hal ini menjadi pembelajaran bagi panitia untuk terus memperbaiki kinerja pembelajaran.

\section{UCAPAN TERIMA KASIH}

Kegiatan PKM ini didanai dan didukung sepenuhnya oleh Universitas Trisakti.

\section{DAFTAR PUSTAKA}

Prelovac, V. (2009). WordPress Plugin Development: Beginners Guide. UK: Packt Publishing ltd.

Sabin-Wilson, L. (2017). WordPress for Dummies ( ${ }^{\text {th }}$ Edition). New Jersey: John Wiley \& Sons, Inc.

Williams, B., Damstra, D., Stern, H. (2015). Professional WordPress: Design and Development (3 ${ }^{\text {rd }}$ Edition). Indianapolis: John Wiley \& Sons, Inc.

Donchev, D. (2017). Canva - Amazing and Simple Graphic Design Perangkat lunak. Digital Marketing. Diambil dari https://fortunelords.com/canva/

Obermeier, B., Padova, T. (2015). Photoshop Elements 13: All-in-One for Dummies. Indianapolis: John Wiley \& Sons, Inc.

Pollock, P. (2013). Web Hosting for Dummies. New Jersey: John Wiley \& Sons, Inc.

Tauhid, A. (2013). Mudah \& Praktis Membuat Website Berbasis CMS. Gratis!. Diambil dari https://ilmukomputer.org/wp-content/uploads/2013/05/tauhid-membuat-website-dengan-mudah.pdf

Terada, E. (2017). 5 Reasons Why We Use Wordpress. Diambil dari https://www.freshconsulting.com/5-reasonswhy-we-use-wordpress/ 